\title{
ORGANIZACYJNE SKUTKI WDROŻENIA ZNORMALIZOWANEGO SYSTEMU ZARZĄDZANIA JAKOŚCIĄ W MAŁYCH I ŚREDNICH PRZEDSIĘBIORSTWACH
}

\begin{abstract}
W ostatnich latach implementacja znormalizowanych systemów zarządzania jakością staje się coraz bardziej popularna również w małych i średnich organizacjach. Praktyka wskazuje jednak, że nie w każdej organizacji systemy zarządzania jakością według normy ISO 9001:2008 funkcjonują skutecznie i efektywnie. W literaturze przedmiotu pojawiają się opinie, że wymagania normy adresowane są przede wszystkim do dużych przedsiębiorstw (najlepiej prowadzących działalność produkcyjna). Głównym celem artykułu jest ukazanie organizacyjnych skutków wdrożenia wymagań systemu zarządzania jakością według normy ISO 9001:2008 w małych i średnich organizacjach.

Wybór grupy docelowej podyktowany był znaczącą rolą, jaką odgrywają małe i średnie organizacje w rozwoju krajowej gospodarki oraz zauważalnym wzrostem wdrożeń systemu zarządzania jakością według normy ISO 9001:2008 przez mniejsze przedsiębiorstwa.

Proces badawczy przeprowadzono na przełomie lipca i sierpnia 2011 r., głównym narzędziem badawczym był kwestionariusz ankietowy. Ankiety przesłano drogą internetową do przedstawicieli kierownictwa 144 małych i średnich organizacji (wypełnione formularze otrzymano od ok. 15\% przedsiębiorstw). Do ostatecznej analizy zakwalifikowano 20 prawidłowo wypełnionych kwestionariuszy ankietowych.

$\mathrm{Na}$ podstawie przeprowadzonych badań wzbogaconych o analizę wyników dostępnych w literaturze stwierdzono, że implementacja znormalizowanego systemu zarządzania jakością według normy ISO 9001:2008 w małych i średnich organizacjach pozytywnie wpływa na usprawnienie procesu obsługi klienta, współpracę z dostawcami, organizację pracy oraz przyjęcie klarownych, przejrzystych celów w obszarze jakości.
\end{abstract}

Słowa kluczowe: ISO 9001, implementacja, system, jakość

\section{WPROWADZENIE}

System zarządzania jakością według normy ISO 9001:2008 jest uznawany za najpopularniejszą koncepcję zarządzania jakością wdrażaną przez przedsiębiorstwa. Jego niewątpliwym atutem jest uniwersalność, pozwalająca dowolnej organizacji na implementację wymagań normy ISO 9001:2008. Praktyka wskazuje jednak, że nie w każdej organizacji systemy zarządzania jakością według normy ISO 9001:2008 funkcjonują skutecznie i efektywnie. W literaturze przedmiotu pojawiają się opinie, że wymagania normy adresowane są przede wszystkim do dużych przedsiębiorstw (najlepiej prowadzących działalność produkcyjną). Jednak na fali popularności normy ISO

${ }^{1}$ Dr Dominik Zimon, Katedra Systemów Zarządzania i Logistyki, Politechnika Rzeszowska, e-mail: zdomin@ prz.edu.pl, al. Powstańców Warszawy 8, 35-959 Rzeszów, tel. (17) 8651073. 
9001:2008kierownicy mniejszych organizacji coraz częściej decydują się na jej implementacje, oczekując po jej wdrożeniu znaczącej poprawy funkcjonowania organizacji.

Celem przeprowadzonych badań była ocena wpływu implementacji wymagań znormalizowanego systemu zarządzania jakością na doskonalenie procesów zarządzania w małych i średnich organizacjach. Wybór grupy docelowej podyktowany był znaczącą rolą, jaką odgrywają małe i średnie organizacje w rozwoju krajowej gospodarki oraz zauważalnym wzrostem wdrożeń systemu zarządzania jakością według normy ISO 9001:2008 przez mniejsze organizacje.

Proces badawczy przeprowadzono na przełomie lipca i sierpnia 2011 r., głównym narzędziem badawczym był kwestionariusz ankietowy. Ankiety przesłano drogą internetową do przedstawicieli kierownictwa 144 małych i średnich organizacji (wypełnione formularze otrzymano od ok. 15\% przedsiębiorstw). Do ostatecznej analizy zakwalifikowano 20prawidłowo wypełnionych kwestionariuszy ankietowych.

\section{WYMAGANIA NORMY ISO 9001:2008 A SPECYFIKA MAŁYCH I ŚREDNICH ORGANIZACJI}

W normie ISO 9001:2008 zawarto ogólne wymagania, jakie powinien spełniać system zarządzania jakością organizacji, która dąży do zaprezentowania swojej zdolności do dostarczenia wyrobu spełniającego wymagania klienta, prowadząc przy tym ciągłe działania doskonalące oraz zapobiegające powstawaniu niezgodności ${ }^{2}$. Za fundament norm z rodziny ISO serii 9000 uznaje się osiem następujących zasad zarządzania jakością:

1. Orientacja na klienta: zasada ta wskazuje na nadrzędną rolę klienta względem organizacji. Kierownictwo i pracownicy powinni mieć świadomość, że rozwój organizacji jest uzależniony od rozpoznania, zrozumienia i spełnienia wymagań klienta.

2. Przywództwo: norma ISO 9001:2008 akcentuje znaczny wpływ, jaki wywiera zaangażowania najwyższego kierownictwa na prawidłowy rozwój organizacji. Ponadto kierownicy są zobligowani do ustalenia celów i polityki jakości, zapewnienia zasobów niezbędnych do spełnienia wymagań klienta, przeprowadzania przeglądów zarządzania itp.

3. Zaangażowanie pracowników: najważniejszym zasobem w myśl postanowień normy ISO 9001:2008 jest personel organizacji dysponujący odpowiednia wiedzą i umiejętnościami oraz aktywnie włączający się $\mathrm{w}$ proces wdrażania $\mathrm{i}$ doskonalenia systemu zarządzania jakością.

4. Podejście procesowe: w celu zwiększenia skuteczności i efektywności organizacji należy zidentyfikować i doskonalić procesy.

5. Podejście systemowe: połączenie procesów w system sprzyja szybszej realizacji nakreślonych celów.

6. Ciągłe doskonalenie: należy rozumieć jako nieustanną pracę wszystkich członków organizacji prowadzącą do rozwoju przedsiębiorstwa, pełniejszego zaspokojenia potrzeb klienta oraz doskonalenia procesów.

\footnotetext{
${ }^{2}$ T. Sikora, Wybrane koncepcje i systemy zarzadzania jakościq, Wydawnictwo Uniwersytetu Ekonomicznego w Krakowie, Kraków 2010, s. 81.
} 
7. Podejmowanie decyzji na podstawie faktów: w celu minimalizacji błędnych decyzji proces decyzyjny powinien być poprzedzony analizą informacji pozyskanych za pomocą pomiarów z wykorzystaniem metod i instrumentów zarządzania jakością.

8. Wzajemne korzystne powiązania z dostawcami: pozytywnie wpływają na jakość produktu lub usługi.

Wdrażając wymagania normy w małych i średnich organizacjach, warto wziąć pod uwagę, że zmagają się one z licznymi ograniczeniami i barierami determinującymi sposób ich funkcjonowania. Należą do nich między innymi ${ }^{3}$ :

1. ograniczone zasoby,

2. presja ze strony większych organizacji,

3. brak jasno określonej strategii działania,

4. problemy z identyfikacją i przyjęciem celów w obszarze jakości,

5. niepewność popytu na oferowane wyroby,

6. ograniczone nakłady na inwestycje,

7. brak wykwalifikowanej kadry,

8. wysokie koszty pozyskiwania kapitałów ze źródeł zewnętrznych.

Ponadto jak zauważa Urban ${ }^{4}$, kierownicy małych i średnich organizacji raczej ostrożnie podchodzą do znormalizowanego systemu zarządzania jakością, obawiając się trudności związanych z jego prawidłowym wdrożeniem i doskonaleniem. Dodatkowo zdaniem autora kadra zarządzająca nie dysponuje odpowiednią wiedzą i nie dostrzega zmian zachodzących w otoczeniu.

\section{WYNIKI I ANALIZA BADAŃ}

Pierwsze $\mathrm{z}$ pytań zadanych respondentom obejmowało problematykę wpływu implementacji wymagań normy ISO 9001:2008 na doskonalenie współpracy w ramach łańcucha dostaw. Odpowiedzi respondentów zawarto w rysunku 1.

Respondenci odpowiadali na pytania w następującej hierarchii ważności: 1 - brak wpływu, 2 - niewielki wpływ, 3- średni wpływ, 4 - duży wpływ, 5 - bardzo duży wpływ. Z rozkładu odpowiedzi wynika, że wdrożenie wymagań normy ISO 9001:2008 wywiera najkorzystniejszy wpływ na proces obsługi klienta. Odpowiedzi tego typu były do przewidzenia, ponieważ znormalizowany system zarządzania jakością w centrum zainteresowania organizacji stawia dobro klienta. Zdaniem Łunarskiego ${ }^{5}$ uruchomiony wraz $\mathrm{z}$ normą system certyfikowania uwiarygodnia organizację $\mathrm{w}$ oczach klienta i potwierdza, że jest ona zdolna spełnić jego wymagania.

Współpraca z dostawcami jest kolejnym obszarem, który można znacząco usprawnić, wdrażając znormalizowany system zarządzania jakością. Norma ISO 9001:2008 wymaga w swych postanowieniach prowadzenia nadzoru nad dostawca, dokonywania oceny oraz wyboru dostawców na podstawie ich zdolności do dostarczania wyrobu zgodnego z

\footnotetext{
${ }^{3}$ D. Zimon, Trudności matych i średnich przedsiębiorstw na etapie wdrażania znormalizowanego systemu zarzqdzania jakościq, ,Zarządzanie Jakością” 2011/3, s. 23.

${ }^{4}$ W. Urban, Dlaczego przedsiębiorstwa stosujq system jakości? Wyniki badań, „Problemy Jakości” 2003/10, s. 46.

${ }^{5}$ J. Łunarski, Zarzadzanie jakościa. Standardy i zasady, WNT, Warszawa 2008, s. 256.
} 
przyjętymi standardami ${ }^{6}$. Działania te mają na celu nie tylko zapewnienie półproduktów optymalnej jakości, ale również mają służyć budowie trwałych i partnerskich relacji z dostawcami.

Rys. 1. Wpływ wdrożenia normy ISO 9001:2008 na doskonalenie współpracy w ramach łańcucha dostaw

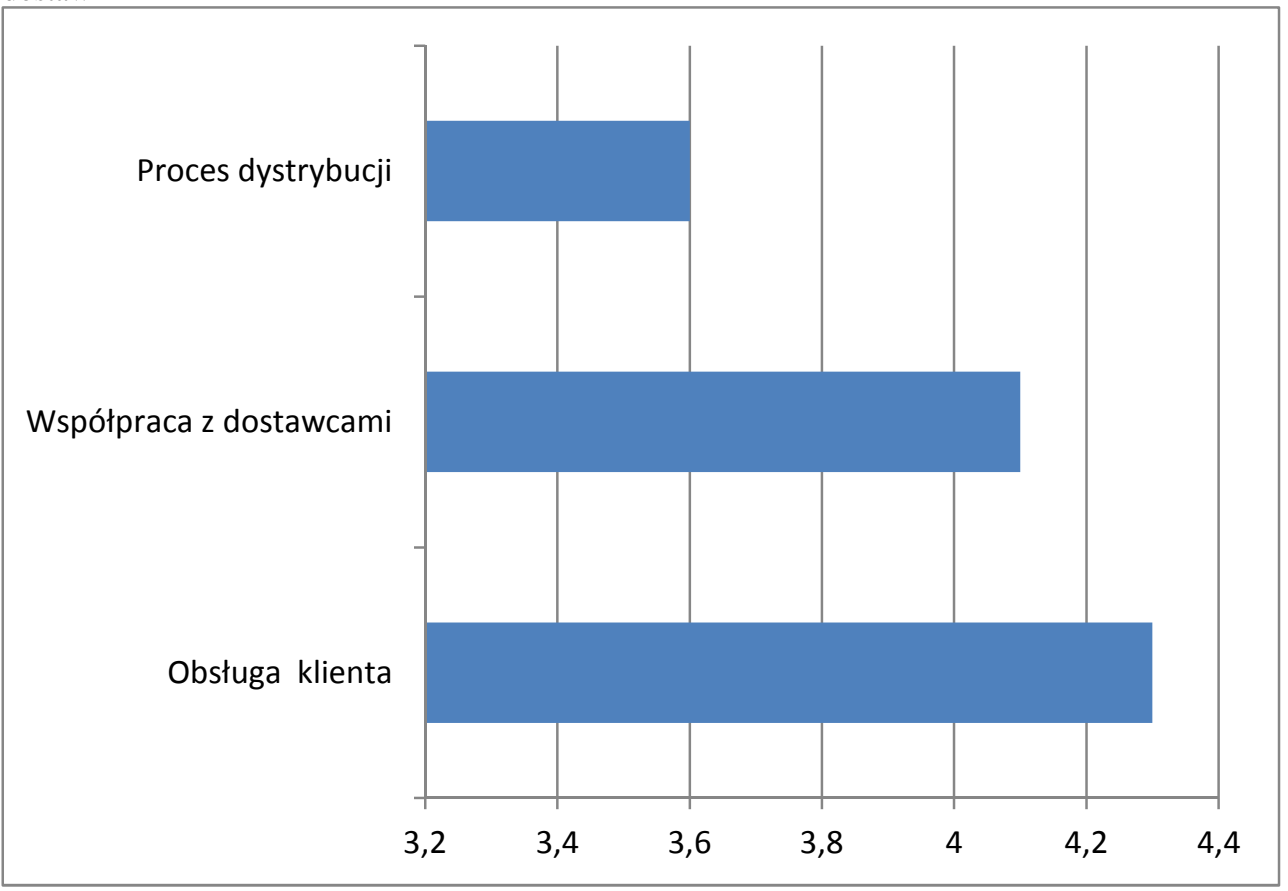

Źródło: opracowanie własne

Najmniej zauważalna (zdaniem respondentów) jest relacja pomiędzy wdrożeniem wymagań systemowych a realizacją procesu dystrybucji. Norma ISO 9001:2008 bazuje bowiem na doskonaleniu wewnętrznych procesów w organizacji, kładąc nacisk na realizację produkcji, obsługę klienta i rozwój kluczowych procesów. Sam proces fizycznej dystrybucji nie jest regulowany postanowieniami normy ISO 9001:2008. Ankietowani twierdzili jednak, że system zarządzania jakością obliguje do badania satysfakcji klienta wynikającej z użytkowania produktu, co wpisuje się w obszar zainteresowania dystrybucji.

Kolejne pytania dotyczyły kwestii wpływu wdrożenia znormalizowanego systemu zarządzania jakością na doskonalenia zarządzania organizacją (rys. 2).

Uzyskane wyniki pozwalają uznać, że wdrożenie wymagań normy ISO 9001:2008 pozytywnie przekłada się na poprawę jakości produktów lub świadczonych usług. Znormalizowany system zarządzania jakością, kładąc duży nacisk na uwzględnienie

\footnotetext{
${ }^{6}$ W. Sokołowicz, A. Srzednicki, ISO. System zarzqdzania jakościq oraz inne systemy oparte na normach, C.H.
} Beck, Warszawa 2006, s. 106. 
wymagań klienta na etapie projektowania produktu, prowadzi do wzrostu zadowolenia konsumenta wynikającego z użytkowania wyrobów dostosowanych do jego potrzeb.

Rys. 2. Wpływ wdrożenia normy ISO 9001:2008 na doskonalenie zarządzania organizacją

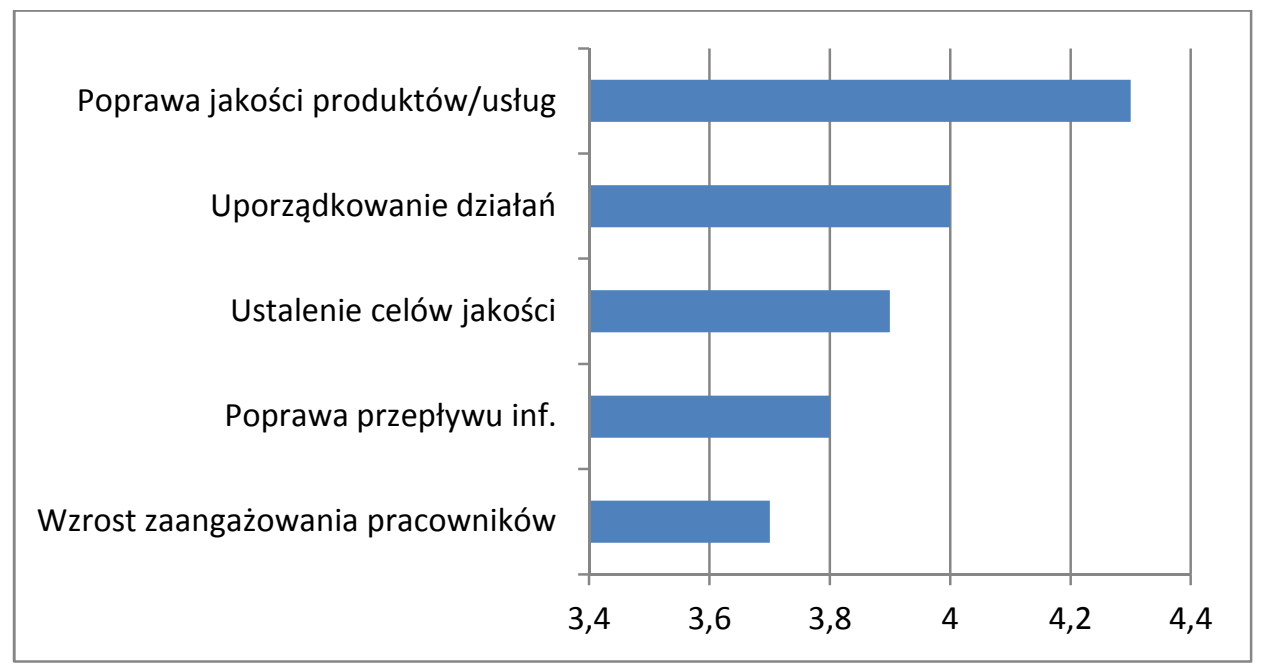

Źródło: opracowanie własne

Z tymi wnioskami korespondują wyniki badań przeprowadzonych przez Jedynaka ${ }^{7}$ na grupie 148 organizacji. Badacz stwierdza w nich, że znormalizowane systemy zarządzania jakością cechują się faktyczną dbałością o potrzeby klienta, co bezpośrednio przekłada się na doskonalenia jakości wyrobów i usług.

Wprowadzenie ładu i porządku organizacyjnego jest kolejną pozytywną stroną implementacji wymagań systemowych. Do podobnych wniosków doszli SkotnickaZasadzień i Witala ${ }^{8}$, którzy na podstawie własnych badań uznają, że jedną $\mathrm{z}$ najważniejszych korzyści wdrożenia systemu zarządzania jakością jest uporządkowanie dokumentacji w przedsiębiorstwie oraz nadanie jej odpowiedniej rangi.

Uporządkowanie działań, przydzielenie odpowiedzialności i obowiązków, wprowadzenie ogólnego ładu wynika z dość restrykcyjnych wymagań dotyczących opracowania dokumentacji systemowej. Przedstawiciele organizacji, przygotowując księgę jakości, poszczególne procedury, instrukcje i zapisy, tworzą pewien schemat zachowań, którym udowadniają, że pracownicy realizują poszczególne wymagania systemu zarządzania jakością. Działania te mają na celu nie tyle opracowanie całkiem nowego systemu, ale raczej na bazie istniejących procesów prowadzą do ustalenia nowych, skuteczniejszych zasad wspólnej pracy osób w organizacji ${ }^{9}$.

\footnotetext{
${ }^{7}$ P. Jedynak, Ocena znormalizowanych systemów zarzadzania jakościq w polskich organizacjach „Problemy Jakości” 2006/3, s. 6.

${ }^{8}$ B. Skotnicka-Zasadzień, A. Witala, Certyfikacja systemu zarzq̨dzania jakościq w matych firmach „Problemy Jakości” 2007/4, s. 44.

${ }^{9} \mathrm{~K}$. Wojtowicz, Organizacyjne skutki potwierdzenia zgodności systemów zarzqdzania jakościa z norma ISO 9000, „Problemy Jakości” 2003/10, s. 46.
} 
Z badań wynika, że norma ISO 9001:2008 wywiera również znaczny wpływ na określenie przez organizację celów, będących podstawą budowy strategii przedsiębiorstwa w obszarze jakości. Kierownictwo organizacji jest zobligowane wymogami normy do opracowania polityki jakości uznawanej za ogólną deklarację informująca, jak przedsiębiorstwo zamierza rozwijać poszczególne obszary jakości. Należy podkreślić, że ustalenie celów i polityki jakości jest najważniejszym, a zarazem jednym z najtrudniejszych etapów opracowania dokumentacji systemowej. Wynika to z tego, że polityka jakości jest kluczowym dokumentem systemowym i pozostała dokumentacja powinna z niej wynikać i być z nią spójna. Należy pamiętać, że prawidłowo opracowany system zarządzania jakością musi zawierać wyraźne przełożenie misji, wizji, strategii i celów przedsiębiorstwa na poziomy procesów, a dalej komórek organizacyjnych, aż do stanowisk pracy włącznie ${ }^{10}$.

Zdaniem ankietowanych wdrożenie znormalizowanego systemu zarządzania jakością miało najmniejszy wpływ na wzrost zaangażowania pracowników. Zaistniałą sytuację można rozpatrywać na kliku płaszczyznach:

1) brak zaangażowania pracowników jest następstwem niewystarczającego nadzoru bądź obojętności kierownictwa,

2) pracownicy nie posiadają odpowiedniej wiedzy na temat wymagań normy ISO 9001:2008 i z tego powodu nie angażują się w proces jej doskonalenia,

3) dokumentację systemową opracowano w pospiechu i nie dostosowano jej do konkretnych stanowisk roboczych, co budzi niechęć pracowników.

Niezależnie od przyczyny, która wpływa na brak zaangażowania pracowników w proces doskonalenia systemu, kierownictwo powinno dołożyć wszelkich starań prowadzących do przełamania ich obojętności. Proces doskonalenia systemu nie może bowiem przebiegać prawidłowo bez aktywnego udziału wszystkich członków organizacji.

$\mathrm{Na}$ koniec warto zaakcentować niezwykle ważną rolę, jaką ma do odegrania kierownictwo małych i średnich organizacji w prawidłowym funkcjonowaniu systemu zarządzania jakością. Do podstawowych zadań najwyższego kierownictwa należy zakomunikowanie wszystkim pracownikom: znaczenia spełnienia wymagań klienta, wymagań ustawowych oraz przepisów. Należy podkreślić, że kierownictwo odgrywa niebagatelną rolę zarówno w samym procesie wdrażania, jak i w późniejszym, obejmującym nadzorowanie prawidłowego funkcjonowania wdrożonego systemu. Natomiast brak należytego zaangażowania ze strony kierownictwa najczęściej prowadzi do wadliwego wdrożenia systemu oraz przekłada się bezpośrednio na brak zaangażowania załogi przedsiębiorstwa w proces budowy i doskonalenia systemu ${ }^{11}$.

\section{PODSUMOWANIE}

Reasumując, należy podkreślić, że wdrażanie systemu zarządzania jakością według normy ISO 9001:2008 pozytywnie wpływa na organizację procesów zarządzania w badanych przedsiębiorstwach. Na podstawie przeprowadzonych badań wzbogaconych o analizę wyników dostępnych w literaturze można przyjąć następujące wnioski:

\footnotetext{
${ }^{10}$ J. Kowalczyk, Konsultant w dziedzinie zarzqdzania jakościq, CeDeWu, Warszawa 2005, s. 36.

${ }^{11}$ D. Zimon, System zarzqdzania jakościq wedtug normy ISO 9001:2008 a specyfika matych i średnich organizacji, [w:] Praktyka zarzqdzania jakościq w XXI wieku, red. T. Sikora, M. Giemza, Wydawnictwo Uniwersytetu Ekonomicznego w Krakowie, Kraków 2012, s. 371.
} 
1) małe i średnie organizacje po wdrożeniu wymagań normy ISO 9001:2008 bardziej świadomie i skuteczniej dbają o relacje z klientem,

2) po wdrożeniu znormalizowanego systemu zarządzania jakością znacząco poprawiła się organizacja współpracy z dostawcami,

3) przestrzeganie wymagań systemowych przez członków organizacji pozytywnie wpływa na poprawę jakości produktów/usług,

4) konieczność opracowania dokumentacji systemowej skutkuje wprowadzeniem ładu organizacyjnego oraz ustalenia przejrzystych celów i polityki jakości.

Prezentowane wnioski znajdują również potwierdzenie $w$ wynikach badań przeprowadzonych przez Urbaniaka ${ }^{12}$, na których podstawie można stwierdzić, że system zarządzania jakością jest dla małych organizacji skutecznym narzędziem zarządzania prowadzącym do doskonalenia procesów, poprawy ich efektywności oraz zmniejszenia liczby reklamacji.

Uwzględniając te rozważania, należy uznać, że norma ISO 9001:2008 z powodzeniem może być wdrażana również w małych i średnich organizacjach. $\mathrm{Z}$ praktycznych doświadczeń wynika jednak, że decyzja o implementacji wymagań systemowych powinna być poprzedzona rzetelną analizą rzeczywistych potrzeb organizacji z uwzględnieniem znacznych nakładów finansowych, jakie są z tym procesem związane. Każda organizacja ma swoją specyfikę oraz odmienne cele i potrzeby, należy mieć to na względzie, decydując się na wybór rozwiązań systemowych, gdyż nie zawsze implementacja wymagań normy ISO 9001:2008 będzie najlepszym rozwiązaniem. Rozważania te potwierdza Lisiecka ${ }^{13}$, uznając, że wdrażanie znormalizowanego systemu zarządzania jakością jest inwestycją i ewentualna decyzja dotycząca implementacji wymagań normy ISO 9001:2008powinna być poprzedzona wielowymiarową analizą jej opłacalności.

\section{LITERATURA}

[1] Jedynak P., Ocena znormalizowanych systemów zarzq̨dzania jakościq $w$ polskich organizacjach, „Problemy Jakości” 2006/3, s. 6.

[2] Kowalczyk J., Konsultant $w$ dziedzinie zarzqdzania jakościq, CeDeWu, Warszawa 2005, s. 36.

[3] Łunarski J., Zarzadzanie jakościq. Standardy i zasady, WNT, Warszawa 2008, s. 256.

[4] Sikora T., Wybrane koncepcje $i$ systemy zarządzania jakościa, Wydawnictwo Uniwersytetu Ekonomicznego w Krakowie, Kraków 2010, s. 81.

[5] Skotnicka-Zasadzień B., Witala A., Certyfikacja systemu zarzqdzania jakościa w matych firmach, „Problemy Jakości” 2007/4, s. 44.

[6] Sokołowicz W., Srzednicki A., ISO. System zarzqdzania jakościq oraz inne systemy oparte na normach, C.H. Beck, Warszawa 2006, s. 106.

[7] Urban W., Dlaczego przedsiębiorstwa stosuja system jakości? Wyniki badań, „Problemy Jakości” 2003/10, s. 46.

\footnotetext{
${ }^{12}$ M. Urbaniak, Uwarunkowania zwiqzane z wdrażaniem systemów jakości przez przedsiębiorstwa dziatajace w Polsce, „Problemy Zarządzania” 2012/2, s. 41.

${ }^{13} \mathrm{~K}$. Lisiecka, Czy certyfikacja systemu jakości wedtug normy ISO serii 9000 się optaca?, „Problemy Jakości” 2003/3, s. 7 .
} 
[8] Urbaniak M., Uwarunkowania zwiqzane z wdrażaniem systemów jakości przez przedsiębiorstwa działajace w Polsce, „Problemy Zarządzania” 2012/2, s. 41.

[9] Wojtowicz K., Organizacyjne skutki potwierdzenia zgodności systemów zarzadzania jakościa z norma ISO 9000, „Problemy Jakości” 2003/10, s. 46.

[10] Zimon D., System zarzqdzania jakościq wedtug normy ISO 9001:2008 a specyfika małych i średnich organizacji, [w:] Praktyka zarzadzania jakościq w XXI wieku, red. T. Sikora, M. Giemza, Wydawnictwo Uniwersytetu Ekonomicznego w Krakowie, Kraków 2012, s. 371.

[11] Zimon D., Trudności matych $i$ średnich przedsiębiorstw na etapie wdrażania znormalizowanego systemu zarzqdzania jakościq, „Zarządzanie Jakością” 2011/3.

\section{ORGANIZATIONAL IMPACT STANDARDISED IMPLEMENTATION OF QUALITY MANAGEMENT SYSTEM IN SMALL AND MEDIUM COMPANIES}

In recent years implementing a normalized quality management system becomes more and more popular even with small organizations. Experience shows, however, that in not every organization quality management system according to ISO 9001:2008 function effectively and efficiently. In the lecture, there are opinions that the requirements of the standards are addressed primarily to large companies (mainly to organizations involved manufacturing).

The purpose of this article is to present the organizational impact of implementing the requirements of ISO 9001:2008 for small and medium-sized enterprises.

Selection of the target group was dictated significant role played by small and medium sized organizations in the development of national economy and a noticeable increase in the quality management system according to ISO 9001:2008 by smaller organizations. The research was conducted in late July and early August 2011, the mail research tool was a questionnaire. Surveys was sent via Internet to the executives of 144 small and medium sized organizations (completed forms were received from approximately $15 \%$ of companies). To the final analysis qualified 20 correctly completed questionnaires surveys.

Based on the results of the study and review of the literature indicated that the implementation of standardized quality management system has a positive effect on the improvement of the customer service process, collaboration with suppliers, work organization and the establishment of clear objectives in the area of quality.

Keywords: ISO 9001, implementation, system, quality.

DOI: 10.7862/rz.2013.mmr.25

Tekst złożono w redakcji: maj 2013

Przyjęto do druku: wrzesień 2013 